\title{
Stability Assessment of a High Speed Permanent Magnet Machine Based Aircraft Electrical Power System
}

\author{
Fei GAO, Seang Shen YEOH, Christopher Ian HILL, Tao YANG, Serhiy BOZHKO \\ University of Nottingham \\ University Park, NG7 2RD \\ Nottingham, United Kingdom \\ Tel: +44 1158468490 \\ Email: eexfg5@nottingham.ac.uk, seang.yeoh@nottingham.ac.uk,C.Hill@nottingham.ac.uk, \\ tao.yang@nottingham.ac.uk, serhiy.bozhko@nottingham.ac.uk \\ URL: http://www.nottingham.ac.uk
}

\section{Acknowledgement}

This research is being conducted in the frame of AEGART Project (No.296090) - a Part of CleanSky JTI FP7 European Integrated Project - http://www.cleansky.eu

\section{Keywords}

« DC power system », « more electric aircraft », « permanent-magnet machine », « stability analysis », « starter/generator »

\begin{abstract}
Starting an aircraft engine with an electrical machine has been one of the major trends for future aircraft. This paper studies the stability of a permanent-magnet machine (PMM) based aircraft starter/generator (S/G) system. Using control-to-output transfer functions, the stability analysis of this $\mathrm{S} / \mathrm{G}$ system is thoroughly studied. The impact of the key parameters including the control parameters is analysed. Simulation and experimental results support the analytical result.
\end{abstract}

\section{Introduction}

The more-electric aircraft (MEA) concept is one of the major trends in modern aerospace engineering aiming for reduction of the overall aircraft weight, operation cost and environmental impact [1], [2]. Electric starter/generator $(\mathrm{S} / \mathrm{G})$ is in alignment with the tendency of moving towards MEA. In the motoring mode, the machine is driven by a power converter and uses the power coming from the supply bus to accelerate the aircraft engine. This mechanical energy may be harnessed to the engine shaft during the engine start cycle and cause the engine to spool up to a speed where the combustion ignites and the engine becomes self-sustaining. In the generating mode, the engine acts as a source of mechanical power that is converted by machine and converter into the electrical power to supply on-board loads. Permanent magnet machine (PMM) has been widely used in automotive propulsion because of its high efficiency, high torque, high power density, and relative ease of field weakening operation [3]-[5]. In [3], an enhanced control strategy of an open-winding $\mathrm{PMM}$ as a $\mathrm{S} / \mathrm{G}$ with the inverter-rectifier topology was proposed to overcome the shortcomings of narrow speed range, and low power factor of traditional PMM. In [4], an optimal design and control of PMM-based SG was proposed to allow a wide constant power zone operation with relatively high efficiencies. In [5], a new PMM has been designed and implemented as S/G for HEVs. Due to the unique feature of hybrid excitations to produce the magnetic field, the proposed PMM can accomplish various operating modes (engine cranking, battery charging, and torque boosting).

In the MEA, the electrical systems are employed to replace existing hydraulic, pneumatic and mechanical power sources. As a consequence, the on-board available electrical power increases significantly. This results 
in great challenges during the design of the electrical power systems (EPS) to ensure its stability and availability. The tendency is to replace traditional AC distribution with high-voltage DC, e.g. $270 \mathrm{~V}$ bus. The merits of a DC system over an AC system include increased efficiency, reduced weight and removing the need for reactive power compensation devices [6], [7]. Many electrical loads within the MEA are tightly controlled by power converters and can often behave like constant-power loads (CPLs). The negative input impedance characteristic of the CPL may result in a reduction of the stability margins of the EPS [8], [9]. Therefore, the candidate EPS control architecture should be carefully examined on stability issues in order to guarantee safe and predictable EPS operation for a wide range of operation scenarios. The stability problems of a PMM based hybrid AC-DC MEA EPS is investigated in [10], [11]. The influence of parameter variation on system stabilities is also presented. Nevertheless, the droop control is not used and the dynamics of the generator is not taken into account.

To fill this gap, this paper deals with the stability analysis of a high speed PMM controlled by a voltage source converter (VSC). The research findings will allow an insightful understanding of the stability problem of the $\mathrm{S} / \mathrm{G}$ system. In addition, a method of tuning the key parameters to ensure wide range stable operation of the PMM-based aircraft starter/generator $(\mathrm{S} / \mathrm{G})$ is presented.

\section{Starter-Generator Architecture and Control Schemes}

Fig .1 shows the studied topology of the MEA EPS. The load consists of resistive loads (representing wing-ice protection systems), typical motor drives (actuators) and tightly regulated DC/DC converters. In the starter mode, the PMM is driven by the VSC. The power flows from the main DC bus to the PMM which cranks the aircraft engine. Once the speed of the engine reaches the firing up speed, the engine will ignited and start to drive the PMM. Under this situation, the PMM behaves as a generator and provides power to the load.

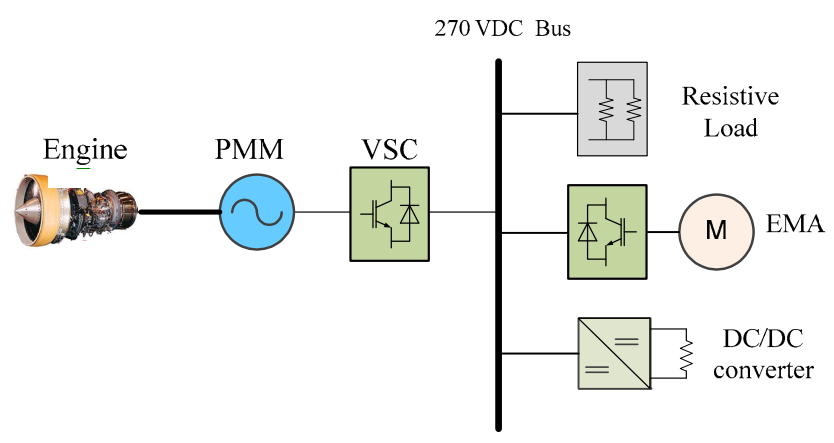

Fig. 1. Starter-generator architecture.

The control scheme for the $\mathrm{S} / \mathrm{G}$ system is shown in Fig. 2. As shown in Fig. 2, fundamental vector control is used in the core system. After transforming measured currents to the synchronous rotating frame, conventional PI controllers adjust currents in $d q$ domain and output $d q$ voltage demands. Voltage demands are inversely transformed into 3-phase demand modulation indexes for PWM. Then the core system can be fully controlled by using both $d q$ current demands.

Fig. 3 shows the outer loop of the S/G. Since the designed PMM is for high speed operation ( $32 \mathrm{krpm})$, a flux weakening controller needs to be taken into account when the machine speed exceeds the base speed. For the starter mode, a speed controller and flux weakening controller are used to generate the respective q-axis current reference and d-axis current reference. When the stator voltage is less than maximum value, the output of the flux weakening controller is saturated to zero. The controller starts to work when the stator voltage exceeds the maximum voltage limit. With the outer voltage regulation loop $\left(V_{c}\right.$ loop), the flux-weakening control is fulfilled by injecting the negative d-axis current.

For the generator mode, conventional PI controllers are used to deflux the machine ( $d$-axis) and control the output DC current ( $q$-axis). The stator current references in $d$ and $q$ axes are obtained from the output of the flux weakening controller and $I_{d c}$ controller respectively. The reference of the ac voltage $\left(V_{c}\right)$ is dependent on the DC voltage. The DC current reference $\left(i_{d c}{ }^{*}\right)$ is determined by the desired droop characteristic. 


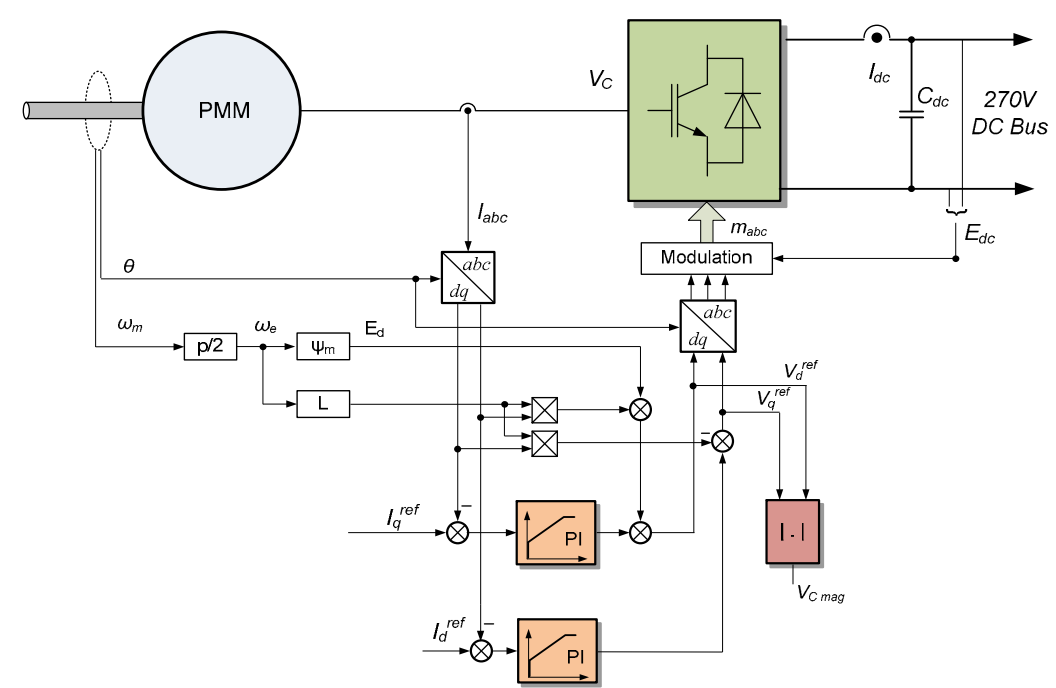

Fig. 2. Control scheme of the core system (Inner current loop).

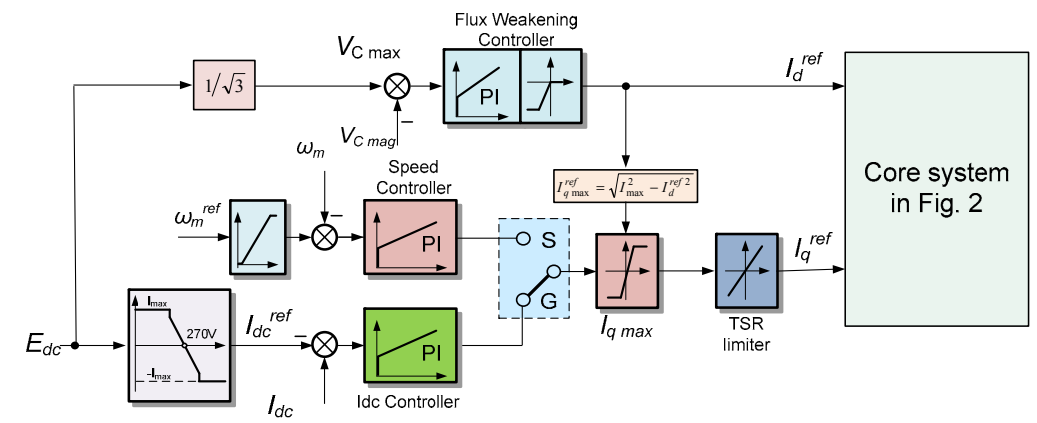

Fig. 3. Outer loop control for the PMM-based S/G.

\section{Stability Analysis for Starter Mode}

The use of a dynamic limiter as part of the control scheme seen in Fig. 2 creates two cases, i.e., $i_{q}{ }^{*}$ not limited or $i_{q}{ }^{*}$ limited. When $i_{q}{ }^{*}$ is limited, the following value is satisfied:

$$
i_{q \max }^{*}=\sqrt{I_{\max }^{2}-i_{d}^{* 2}}
$$

This section will derive the control-to-output transfer function $\left(\partial V_{c}\right.$ to $\left.\partial i_{d}{ }^{*}\right)$ for both cases as they usually happen during the $\mathrm{S} / \mathrm{G}$ operation. After developing the models and corresponding transfer function, the limit for the flux weakening controller is analysed.

\section{A. $i_{q}{ }^{*}$ not limited case}

For the $i_{q}{ }^{*}$ not limited mode, the control block diagram is presented in Fig. 4. $P I_{c}, P I_{f w}$, and $P I_{w}$ represent the PI controller for the current loop, flux weakening loop, and speed loop, respectively.

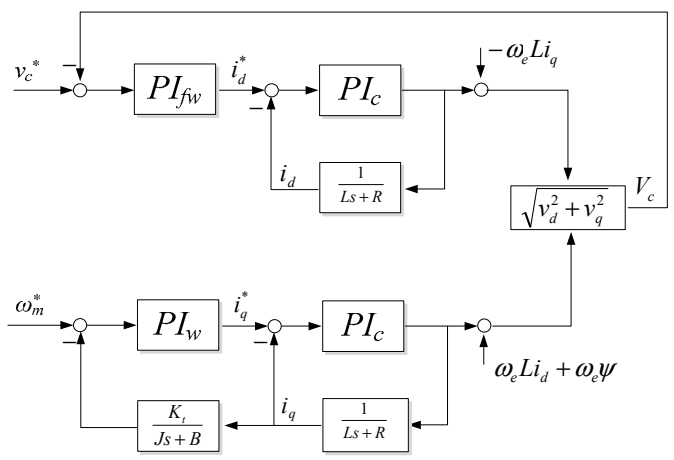

Fig. 4. Control block diagram of the system in starter mode, $i_{q}{ }^{*}$ not limited. 
The $d$-axis and $q$-axis controllers work independently. Using classical vector control in the $d q$ frame, the $d$-axis and $q$-axis stator voltages yield:

$$
\left\{\begin{array}{l}
v_{d}=\left(R_{s}+L_{s} s\right) i_{d}-\omega_{e} L_{s} i_{q} \\
v_{q}=\left(R_{s}+L_{s} s\right) i_{q}+\omega_{e} L_{s} i_{d}+\omega_{e} \varphi_{m} \\
V_{c}=\sqrt{v_{d}^{2}+v_{q}^{2}}
\end{array}\right.
$$

where $R_{S}$ is the stator resistance; $L_{S}$ is the stator inductance; $\varphi_{m}$ is the flux linkage of the permanent magnet; $\omega_{e}$ is the electrical rotor angular velocity in $\mathrm{rad} / \mathrm{s} ; v_{d}, v_{q}$ are the $d$-axis, $q$-axis component of stator voltage; $V_{c}$ is the stator voltage magnitude; $i_{d}, i_{q}$ are the $d$-axis, $q$-axis component of stator current. The inner current loop $i_{d q}$ can be designed based on a specific control bandwidth $\omega_{n c}$ and damping ratio $\zeta$ :

$$
G_{i d q}=\frac{i_{d q}^{*}}{i_{d q}}=\frac{k_{p c} s+k_{i c}}{\left(L_{s} s^{2}+\left(R_{s}+k_{p c}\right) s+k_{i c}\right)}=\frac{\left(k_{p c} s+k_{i c}\right) / L_{s}}{s^{2}+2 \xi \omega_{n c} s+\omega_{n c}^{2}}
$$

where $k_{p c}$ and $k_{i c}$ are the proportional gain and integral gain of the inner current controller, respectively. The equations are linearised around an operating point using Taylor's series for small signal analysis. The linearised control-to-output transfer function for the FW control has been derived and given as follows:

$$
\frac{\partial V_{c}}{\partial i_{d}^{*}}=G_{i d q} \frac{\left(s+R_{s} / L_{s}+v_{q 0} / v_{d 0} \omega_{e}\right)}{v_{d 0} L_{s}^{2} V_{c 0}}
$$

where $\omega_{n c}$ is the inner current loop bandwidth; $\zeta$ is the damping ratio of the inner current loop. The subscript "0" denotes the operating point of that variable. Since $v_{q 0}$ is positive and $v_{d 0}$ is negative when operating in starter mode, it can be seen that a right-half plane (RHP) zero $z_{1}$ exists in the plant upon testing with various operating points:

$$
z_{1}=-\frac{R_{s}}{L_{s}}-\frac{v_{q o} \omega_{e}}{v_{d o}}
$$

This RHP zero imposes control design challenges, especially when trying to aim for fast response of the FW controller (high gain instability) or the inclusion of proportional gain.

Fig. 5 shows the root locus at different loads with respect to the gain of the FW controller $P I_{f w}$. The load demands investigated were at $10 \mathrm{Nm}, 25 \mathrm{Nm}$, and $40 \mathrm{Nm}$ to cover the effect of different levels of load torque on the $\mathrm{S} / \mathrm{G}$ system. It shows the gain limit of the FW controller in presence of the RHP zero $\mathrm{z}_{1}$. Due to the slower positive zero at higher loads, the allowable range for $k_{i v}$ gain is reduced. The upper threshold value for $k_{i v}$ gain reduces to 8000 as the load torque increases to $40 \mathrm{Nm}$.

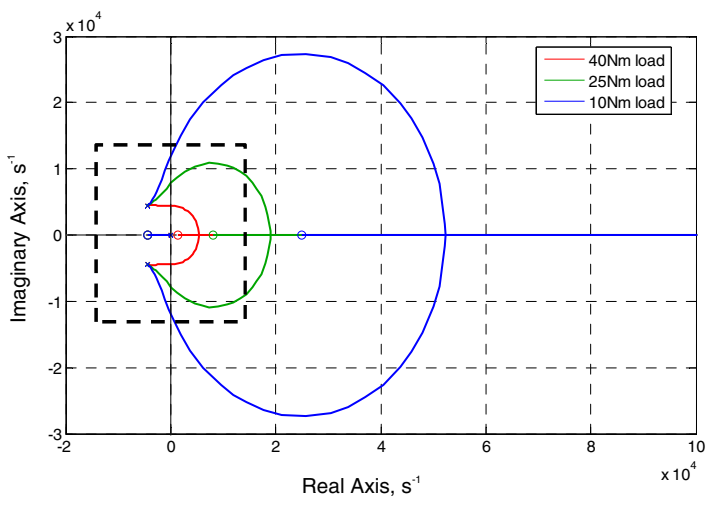

(a)

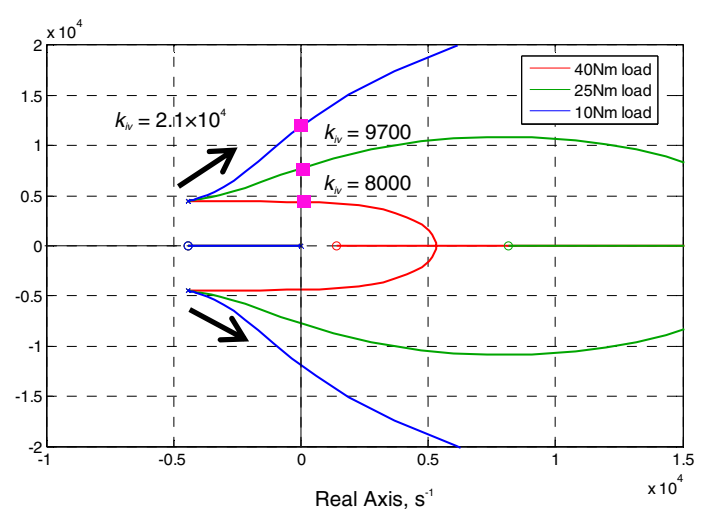

(b)

Fig. 5. Root loci with respect to the gain of the FW controller $\left(k_{i v}\right)$ when $i_{q}{ }^{*}$ is not limited. (a) Overview. (b) Zoomed part of selected area.

As a short summary here, the RHP zero poses some challenges to the design of the flux weakening control in starting mode. 


\section{B. $i_{q}{ }^{*}$ limited case}

For limited $i_{q}{ }^{*}$ mode, Fig. 6 shows the control block diagram and the control-to-output transfer function can be derived as:

$$
\frac{\partial V_{c}}{\partial i_{d}^{*}}=G_{i d q} \frac{1}{V_{c 0} L_{0}}\left\{s L_{s}\left(v_{d 0}+\frac{v_{q 0} i_{d 0}}{\sqrt{I_{\max }^{2}-i_{d 0}^{2}}}\right)+v_{d 0} R_{s}+\frac{v_{q 0} R_{s} i_{d 0}}{\sqrt{I_{\max }^{2}-i_{d 0}^{2}}}+\omega_{e} L_{s}\left(v_{q 0}-\frac{v_{d 0} i_{d 0}}{\sqrt{I_{\max }^{2}-i_{d 0}^{2}}}\right)\right\}
$$

Fig. 7 shows the root locus with respect to the gains of the FW controller under different loads. For loads $10 \mathrm{Nm}$ and $25 \mathrm{Nm}$, the plant was found to be minimum phase; there is no gain limit for the FW controller. The plant is non-minimum phase at an operating load of $40 \mathrm{Nm}$ and a limited FW controller gain stability is present. It can be seen that the eigenvalues would be in the RHP if the integral gain $k_{i v}$ exceeds 8400 . This indicates that the FW plant in $i_{q}{ }^{*}$ limited mode is generally minimum phase and is non-minimum phase when operating at high loads $(40 \mathrm{Nm})$. The zero that determines the characteristic of the FW plant in $i_{q}{ }^{*}$ limited case is expressed as:

$$
z_{2}=-\frac{i_{d 0}\left(L_{q} v_{d 0} \omega_{e 0}-R_{s} v_{q 0}\right)+i_{q 0}\left(L_{d} v_{q 0} \omega_{e 0}+R_{s} v_{d 0}\right)}{i_{q 0} L_{d} v_{d 0}-i_{d 0} L_{q} v_{q 0}}
$$

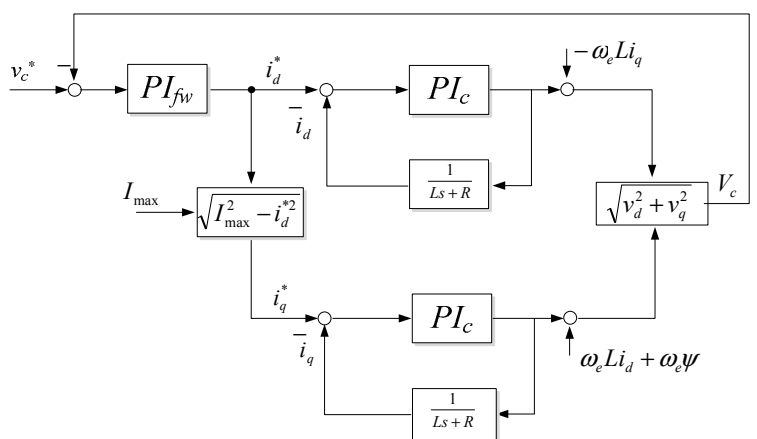

Fig. 6. Control block diagram of the system in starter mode, $i_{q}$ limited.

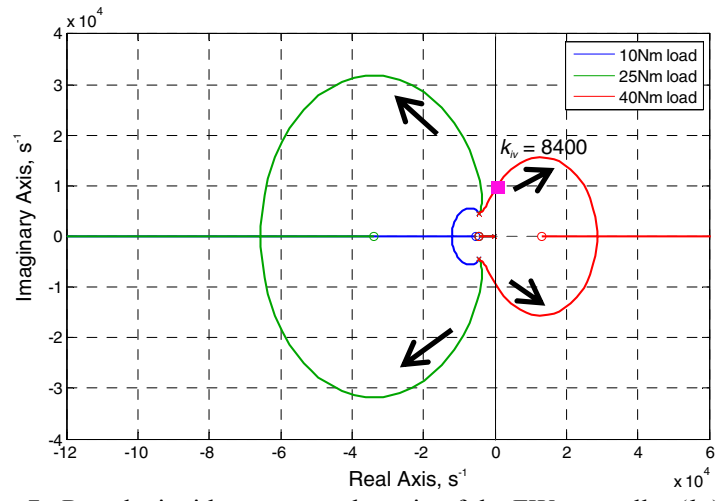

Fig. 7. Root loci with respect to the gain of the FW controller $\left(k_{i v}\right)$ when $i_{q}{ }^{*}$ is limited.

Comparing between both modes, $i_{q}{ }^{*}$ not limited has a smaller gain range. Adapting the FW controller gains according to the operating load for both of these cases would pose a challenge to the system stability. If $k_{i v}$ is within the gain range covering the load series, this would ensure stable FW control. Thus, the design of the FW controller in $i_{q}{ }^{*}$ not limited should cover stable operation of the FW controller for both current modes.

\section{Stability Analysis for Generator Mode}

Similarly, the stability analysis was conducted in generator mode. This section will show the effect of the RHP zero on the DC current controller and droop controller [15]. The upper and lower boundaries of the droop gain are established. In addition, the impact of varying generator speed on the system is discussed.

\section{A. $i_{q}{ }^{*}$ not limited case}

For the $i_{q}{ }^{*}$ not limited case in generator mode, the speed controller is replaced by the DC current controller which aims to regulated the active power. Fig. 8 shows the control scheme for the EPS in generator mode. 


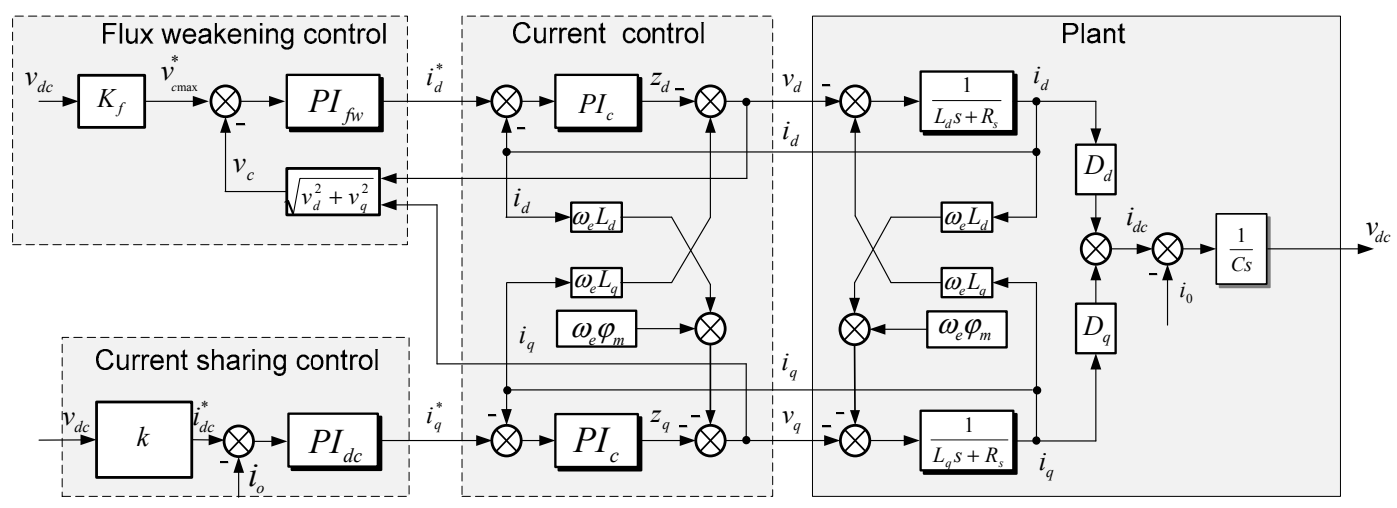

Fig. 8. Control block diagram for the generator mode [14].

Fig. 9 shows the equivalent control block diagram for generating mode. The output of the voltage droop controller is the DC current reference $\left(i_{d c}{ }^{*}\right)$ and the DC current is regulated by a PI controller $G_{I d c}$.

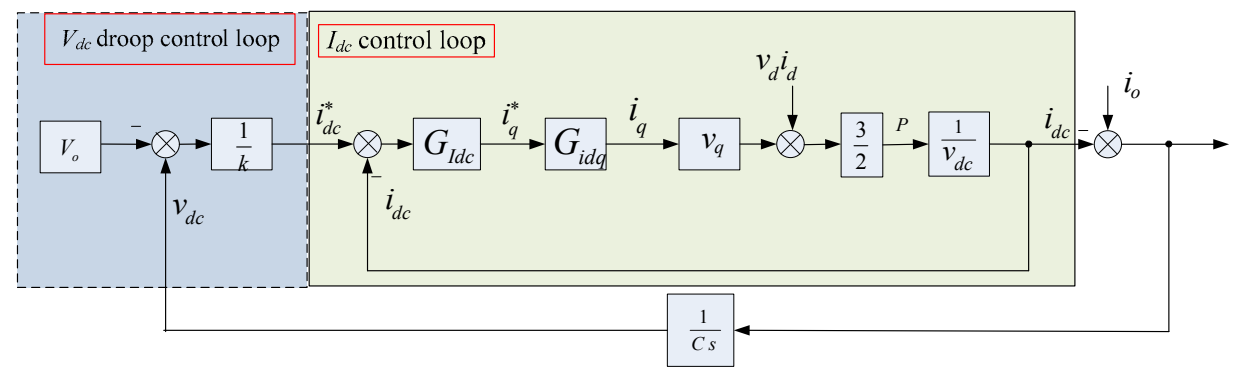

Fig. 9. Control block diagram for the generator mode.

After linearising the system in generator mode, as shown in Fig. 9, Fig. 10 shows the linearised control block diagram for generating mode. The control-to-output $G_{P_{-} C}$ can be expressed as:

$$
G_{P_{-} C}=\frac{\partial i_{d c}}{\partial i_{q}^{*}}=\frac{-3 V_{d c 0} C s\left(k_{p c} s+k_{i c}\right)\left(i_{q 0} L_{s} s+R_{s} i_{q 0}+v_{q 0}\right)}{2\left(L_{s} s^{2}+\left(k_{p c}+R_{s}\right) s+k_{i c}\right)\left(V_{d c 0}^{2} C s-P_{0}\right)}
$$

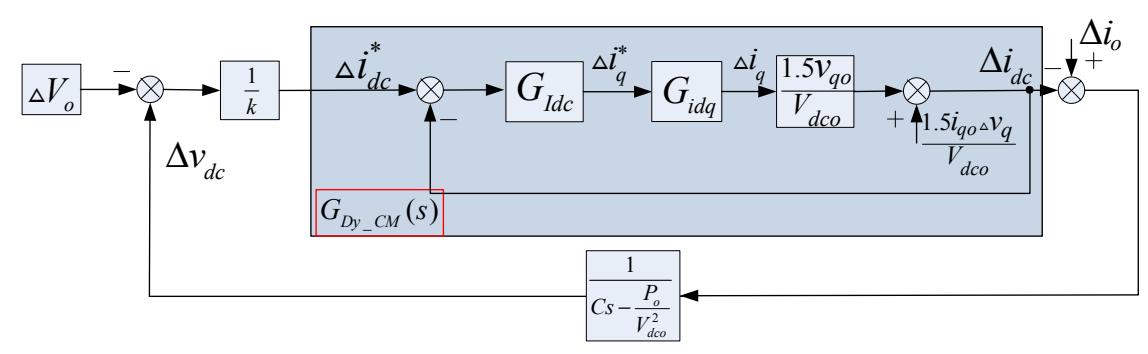

Fig. 10. Linearized control block diagram of the generator mode.

Due to the term $\left(L_{s} i_{q 0} \mathrm{~S}+R_{s} i_{q 0}+v_{q 0}\right)$ in the control-to-output transfer function ( $i_{q 0}$ is negative in the generator mode and $v_{q 0}$ is positive at the operating point), a positive right half plane (RHP) zero $\mathrm{z}_{3}$ exists in the $I_{d c}$ control loop which can be expressed as:

$$
z_{3}=-\frac{v_{q 0}+R_{s} i_{q 0}}{L_{s} i_{q 0}}
$$

The root locus with respect to the gain of DC current controller is shown in Fig. 11. It can be seen that this RHP zero imposes high gain instability for the DC current controller, i.e., the gain cannot exceed a certain value in order to ensure stable operation. 


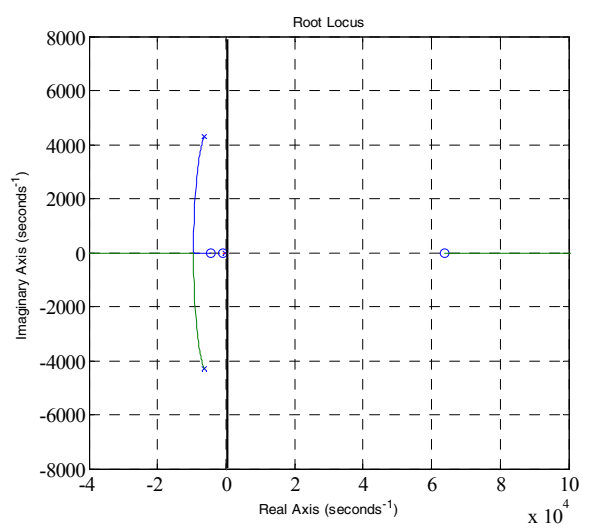

Fig. 11. Root loci with respect to the gain of DC current controller.

Decreasing the droop gain $k$ reduces the steady-state DC voltage error and increases the voltage-loop bandwidth. However, this also reduces the damping and robustness of the system, leading to a lower boundary for the droop gain. This effect can be explained from the standpoint of control design. Droop gain is effectively a proportional controller. As shown in Fig. 10, the inverse of the droop gain can be regarded as the proportional gain of the DC voltage controller. This instability is because some of the system eigenvalues will be in the RHP if the inverse of droop gain $(1 / k)$ increases over a threshold value. Fig. 12 shows the root contour with respect to the proportional gain $(1 / k)$. It can be seen from Fig. 12 that the droop gain has an lower limitation due to the existing RHP zero, which demonstrates that the system is unstable when the inverse of droop gain $1 / k$ is higher than 50 ( $k$ is lower than $1 / 50)$.

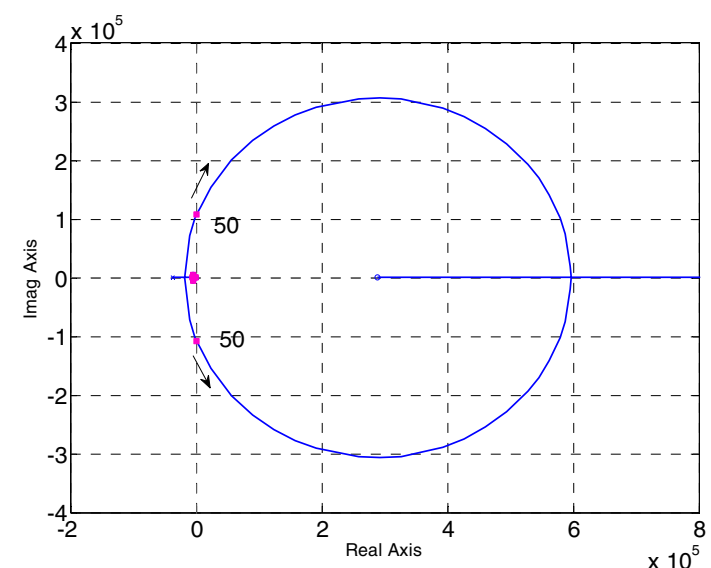

Fig. 12. Root loci with respect to the droop gain.

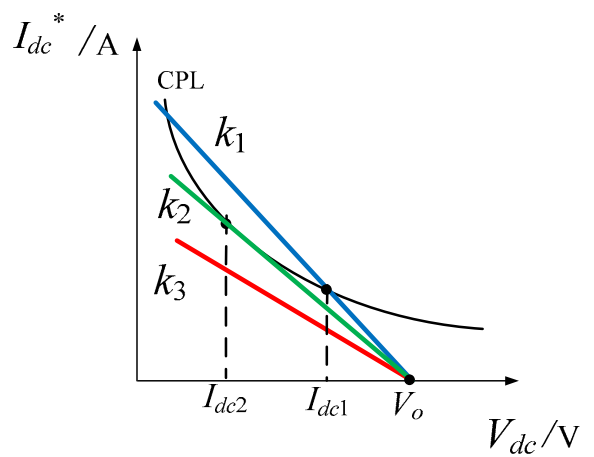

Fig. 13. Interaction between the droop-controlled source system and CPL.

It is known that a larger droop coefficient will cause more voltage deviation and therefore the system needs to be designed carefully in order to ensure the equilibrium point is achievable according to the load power. As shown in Fig. 13, the V-I characteristic can be expressed as:

$$
V_{b}=V_{o}-k I_{o}
$$

where $V_{b}$ is the dc bus voltage and $I_{o}$ is the load current. For the load side, a CPL creates a hyperbolic line which can be expressed as:

$$
P_{C P L}=V_{b} I_{o}
$$

where $P_{C P L}$ is the power of the CPL. The overall system can operate normally only if the two curves have an intersection point (equilibrium point). The stable equilibrium point can be derived as follows:

$$
V_{b}=\frac{1}{2}\left(V_{o}+\sqrt{V_{o}^{2}-4 k P_{C P L}}\right), \quad I_{o}=\frac{1}{2 k_{i}}\left(V_{o}-\sqrt{V_{o}^{2}-4 k P_{C P L}}\right)
$$

Fig. 13 shows that a larger droop constant will cause bigger bus voltage deviation and can even result in there being no intersection point between the source curve and CPL curve (for example the $k_{3}$ curve). As a 
consequence, no steady-state solution can be found, leading to instability. Using (12), the maximum droop gain can be derived as:

$$
k<\frac{V_{o}^{2}}{4 P_{C P L}}
$$

\section{B. $i_{q}{ }^{*}$ limited case}

When the system operates with a large load deep within the flux weakening region (needs more negative $i_{d}$ to deflux the machine), the system tends to enter the $i_{q}{ }^{*}$ limited case. However, it is rare for the power system to operate in this case. The electrical load requirements for the $\mathrm{S} / \mathrm{G}$ system reach up to $40 \mathrm{~kW}$ in which $i_{q}{ }^{*}$ demand is well within $I_{\max }$. Thus, it can be summarized here that the existing RHP zero in generator mode $i_{q}{ }^{*}$ not limited case imposes the upper boundary of droop gain.

\section{Simulation Studies}

Simulation studies of the PMM-based starter/generator system have been performed using Matlab/Simulink.

\section{A. Starter Mode}

The gain stability range verification for the FW controller can be seen in Fig. 14. Load torque, $T_{L}$, is added in step increments of $5 \mathrm{Nm}$ every $0.5 \mathrm{~s}$ until it reaches $40.5 \mathrm{Nm}$ at $t=6.5 \mathrm{~s}$. At this point the power system is operating in limited $i_{q}{ }^{*}$ case. At $t=7 \mathrm{~s}$ the FW controller gain, $k_{i v}$, is increased gradually from 8000 to 8700 and instability can be observed on the AC magnitude voltage, $V_{c}$. The linear transfer function (6) confirms the gain stability range and stability is restored when $k_{i v}$ is reduced back to 8000 .

\section{B. Generator Mode}

This subsection will show the effect of the droop gain on stability in generating mode. Fig. 15 shows the simulation result of the generator mode under varying droop gain, $k$. The bus capacitance is set to $0.3 \mathrm{mF}$. It can be seen that normal operation can be guaranteed when a small droop gain (1/8.5) is applied. The oscillation appears at $t=0.2 \mathrm{~s}$ when the droop gain is reduced to $1 / 50$ which confirms the destabilizing effect of the decreased droop gain. After $t=0.25 \mathrm{~s}$, the system restores stable operation when the droop gain is adjusted to $1 / 10$. However, the system tends to be unstable again when the droop gain is set to $1 / 4$. Large voltage drop on the DC bus is also visible from Fig. 16 at the heavy load after $t=0.3 \mathrm{~s}$. This result verifies the stability limitation imposed by the RHP zero in the control-to-output transfer function $\left(\partial I_{d c}\right.$ to $\left.\partial i_{q}{ }^{*}\right)$.
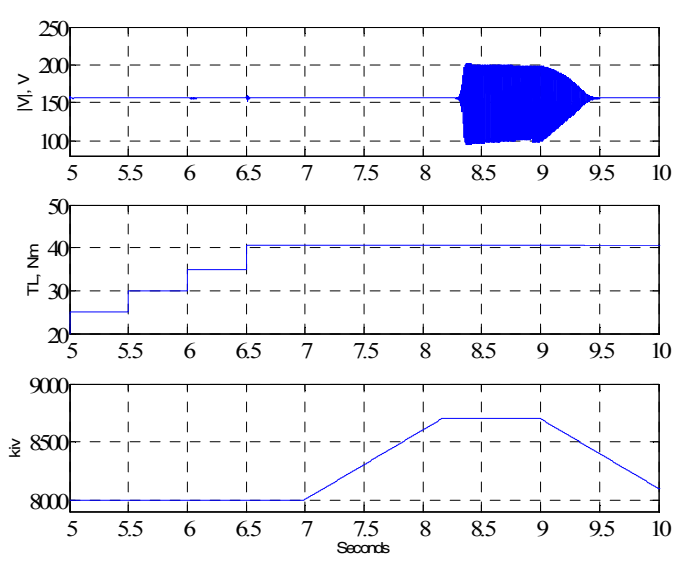

Fig. 14. Simulation result of varying $k_{i v}$ in starter mode, $i_{q}{ }^{*}$ limited.
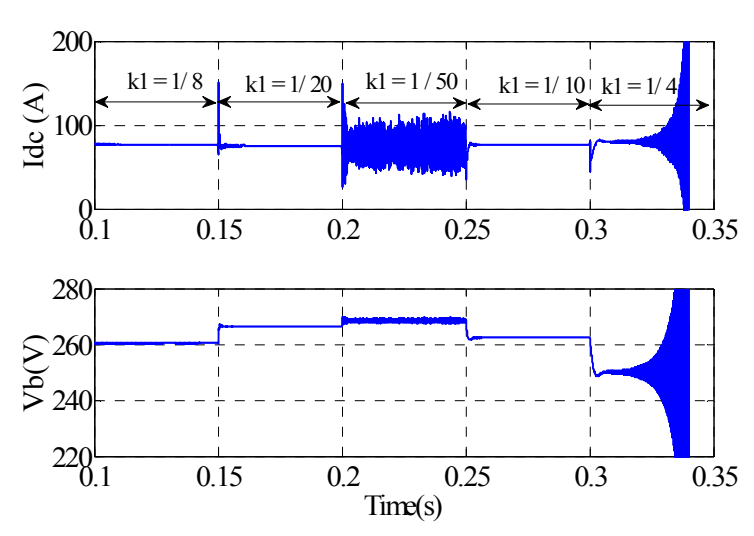

Fig. 15. Simulation result for varying $k_{D}$ in generator mode.

\section{Experimental Results}

To validate the theoretical analysis, a prototype of PMM-based S/G was built. The prototype parameters can be found in the Appendix. The experiments are aimed at validating the stable gain range of the $\mathrm{S} / \mathrm{G}$ controllers (for FW and DC link control). The controllers for this prototype are designed based on the process described in this paper. 


\section{A. Starter Mode - FW controller}

In this sub-section, the FW controller gain range during different operating modes and current limit cases will be verified. The FW controller is included as part of the control scheme for the $\mathrm{S} / \mathrm{G}$ system. $i_{q}{ }^{*}$ is set manually in order to determine the operational mode; positive values for starter mode, negative values for generator mode. $k_{i v}$ is then modified in order to exceed the gain limit at a specific operating point. Increased oscillations within the $i_{d}$ and $V_{c}$ responses are expected, indicating instability in the FW controller. For the stable regions that are not limited due to minimum phase nature, the $k_{i v}$ step is just set to a large value.

Fig. 16(a) shows the results of the $k_{i v}$ step change when the drive system is operating in starter mode. A load demand of $i_{q}=4 \mathrm{~A}$ was connected to ensure operation in starter mode. The gain range was found to be 750 . The value of $k_{i v}$ is initially set to 650 which is below the stability boundary limit, and then changed to 700 at about $t$ $=0.44 \mathrm{~s}$. It can be seen that $V_{c}$ and $i_{d}$ experienced increased oscillations which indicate instability after the $k_{i v}$ step change. The instability occurred slightly below the expected gain range; this may be due to parameter variation within the PMM. Only the FW controller was affected as $i_{q}$ was still stable.

The test is also performed for limited $i_{q}{ }^{*} . I_{\max }$ is reduced until the required operating point is reached where $i_{q}=$ 4A. $k_{i v}$ is changed to 1000 from an initial value of 100 at $t=0.23 \mathrm{~s}$ and the results can be seen in Fig. 16(b). Stable operation is observed despite the large step change in $k_{i v}$. The experimental results presented confirm the $k_{i v}$ gain range and phase nature of the $\mathrm{S} / \mathrm{G}$ system operating in starter mode under both current cases.
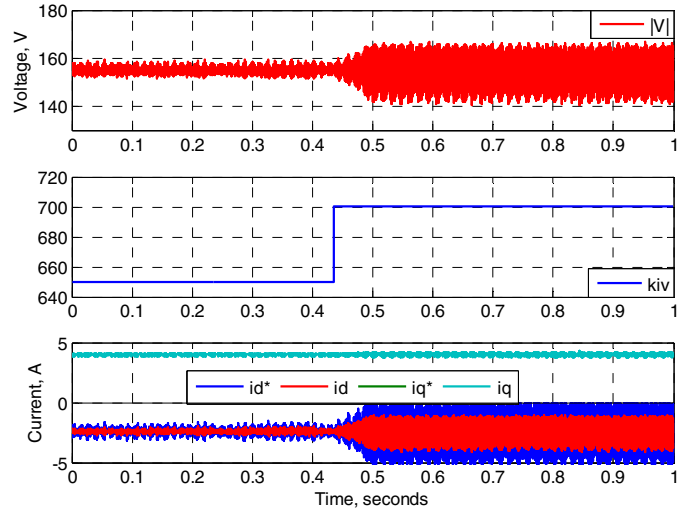

a)
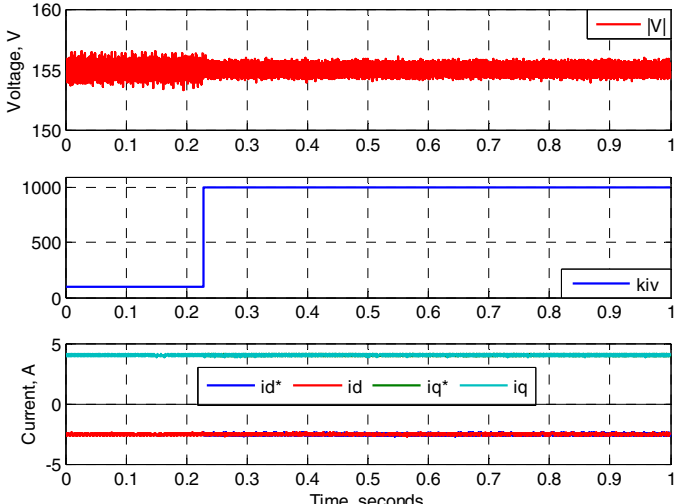

b)

Fig. 16. $k_{i v}$ range validation for starter mode $i_{q}{ }^{*}$ a) not limited and b) limited operating at 3.6krpm.

\section{B. Generator Mode - Droop Gain}

As discussed in previous sections, the existing RHP zero will pose a challenge to the droop controller in generator mode. This subsection will demonstrate the effect of droop gain and Fig. 17 shows the experimental result. Before $t=0 \mathrm{~s}$, the system is working with a $2 \mathrm{~kW}$ load. Droop gain is gradually reduced from 1 to 0.03 . When $k_{1}$ becomes equal to 0.03 , the system becomes oscillatory and eventually unstable due to the nonminimum phase property and the protection stops the system. The result matches the stability prediction regarding to the effect of droop gain.
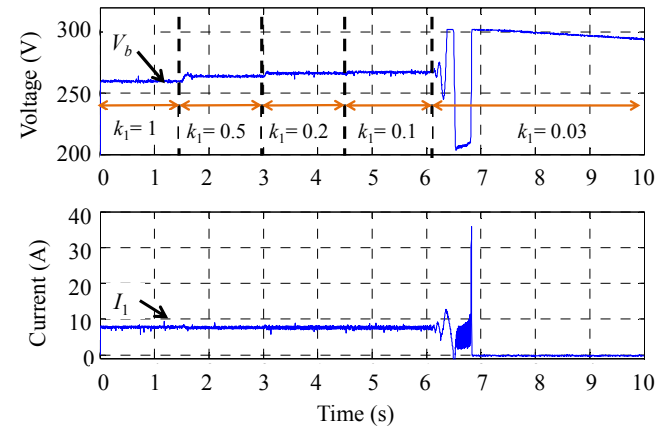

Fig. 17. Experimental results with varying droop gains in generator mode.

\section{Conclusion}


The paper developed the model of a PMM-based aircraft electrical power system. Based on the model, the control-to-output transfer functions have been derived and the non-minimum phase property has been investigated in both $\mathrm{S} / \mathrm{G}$ modes. Simulation studies and experimental tests have been conducted to support the theoretical analysis. The main findings of this paper can be highlighted as follows:

(1) The existing RHP zero limits the gain of the FW controller in starter mode and it varies according to the operating point.

(2) The droop gain has a lower limit due to the non-minimum phase property of the system and also a higher limit due to the DC bus electrical specifications.

\section{Appendix}

\section{EXPERIMENTAL RIG PARAMETERS}

\begin{tabular}{|l|l|c|c|}
\hline Category & Parameter & Symbol & Value \\
\hline PMM & Machine resistance & $R_{s}$ & $1.2 \Omega$ \\
\cline { 2 - 4 } & d-axis machine inductance & $L_{d}$ & $6.12 \mathrm{mH}$ \\
\cline { 2 - 4 } & q-axis machine inductance & $L_{q}$ & $8.379 \mathrm{mH}$ \\
\cline { 2 - 4 } & Flux linkage of permanent magnet & $\varphi_{m}$ & $0.23 \mathrm{~V}^{*} \mathrm{~s} / \mathrm{rad}$ \\
\cline { 2 - 4 } & Number of poles & $p$ & 6 \\
\cline { 2 - 4 } & Nominal power & $P_{N}$ & $2.5 \mathrm{~kW}$ \\
\cline { 2 - 4 } & Maximum speed & $\omega_{\max }$ & $4 \mathrm{krpm}$ \\
\hline Stator current loop & $i_{d}$ controller proportional gain & $K_{i d p}$ & 13.8 \\
\cline { 2 - 4 } & $i_{d}$ controller integral gain & $K_{i d i}$ & 9470 \\
\cline { 2 - 4 } & $i_{q}$ controller proportional gain & $K_{i q p}$ & 18.7 \\
\cline { 2 - 4 } & $i_{q}$ controller integral gain & $K_{i q i}$ & 12543 \\
\hline
\end{tabular}

\section{References}

[1] J. A. Rosero, J. A. Ortaga, E. Aldabas, and L. Romeral, "Moving towards a more electric aircraft", IEEE Aerosp. Electron. Syst. Mag., vol. 22 , no. 3, pp. 3-9, Mar. 2007.

[2] P. Wheeler and S. Bozhko, "The more electric aircraft: technology and challenges," IEEE Electrification Magazine, vol. 2, no. 4, pp. 6-12, Dec. 2014.

[3] Wei, Q. Deng, B. Zhou, M. Shi, and Y. Liu, "The control strategy of open-winding permanent magnet starter-generator with inverter-rectifier topology," IEEE Trans. Ind. Inform., vol. 9, no. 2, pp. 983-991, May 2013.

[4] L. Chedot, G. Friedrich, J. M. Biedinger, and P. Macret, "Integrated starter generator: The need for an optimal design and control approach. application to a permanent magnet machine," IEEE Trans. Ind. Appl., vol. 43, no. 2, pp. 551-559, Mar./Apr. 2007.

[5] C. Liu, K. T. Chau, and J. Z. Jiang, "A permanent-magnet hybrid brushless integrated starter-generator for hybrid electric vehicles," IEEE Trans. Ind. Electron., vol. 57, no. 12, pp. 4055-4064, Dec. 2010.

[6] C. Wang, X. Li, L. Guo, and Y. Li, "A nonlinear-disturbance-observer-based DC-bus voltage control for a hybrid AC/DC microgrid," IEEE Trans. Power Electron., vol. 29, no. 11, pp.6162-6177, Nov. 2014.

[7] H. Kakigano, Y. Miura, and T. Ise, "Low-voltage bipolar-type DC microgrid for super high quality distribution," IEEE Trans. Power Electron., vol. 25 , no. 12, pp. 3066-3075, Dec. 2010.

[8] A. Emadi, A. Khaligh, C. Rivetta, and G. Williamson, "Constant power loads and negative impedance instability in automotive systems: Definition, modeling, stability, and control of power electronic converters and motor drives," IEEE Trans. Veh. Technol., vol. 55, no. 4, pp. 11121125, Jul. 2006.

[9] P. Liutanakul, A. Awan, S. Pierfederici, B. Nahid-Mobarakeh, and F. Meibody-Tabar, "Linear stabilization of a DC bus supplying a constant power load: A general design approach," IEEE Trans. Power Electron., vol. 25, no. 2, pp. 475-488, Feb. 2010.

[10] K-N. Areerak, T. Wu, S. V. Bozhko, G. M. Asher, and D. W. P. Thomas, "Aircraft power system stability study including effect of voltage control and actuators dynamic," IEEE Trans. Aerosp. Electron. Syst., vol. 47, no. 4, pp. 2574-2589, Oct. 2011.

[11] K-N. Areerak, S. V. Bozhko, G. M. Asher, L. De Lillo, and D. W. P. Thomas, "Stability study for a hybrid AC-DC more-electric aircraft power system," IEEE Trans. Aerosp. Electron. Syst., vol. 48, no. 1, pp. 329-347, Jan. 2012.

[12] L. Han, J. Wang, and D. Howe, "Small-signal stability studies of a 270V DC more-electric aircraft power system," in Proc. Power Electronics Machines and Drives 2006. The 3rd IET International Conference (PEMD), Apr. 2006, pp. 197-201.

[13] S. Bozhko, S. Yeoh, F. Gao, and C. Hill, "Aircraft starter-generator system based on permanent-magnet machine fed by active front-end rectifier," in Industrial Electronics Society, IECON 2014 - 40th Annual Conference of the IEEE, Dallas, USA, Oct. 2014, pp.2958-2964.

[14] X. Zheng, F. Gao, and S. Bozhko, "Stability study of a DC electric power system with paralleled generators for more-electric aircraft," SAE Technical Paper 2014-01-2114, SAE International, Sep. 2014.

[15] J. M. Guerrero, M. Chandorkar, T.-L. Lee, and P. C. Loh, "Advanced control architectures for intelligent microgrids-Part I: Decentralized and hierarchical control," IEEE Trans. Ind. Electron., vol. 60, no. 4, pp. 1254-1262, Apr. 2013. 